\title{
Antibacterial activity of the novel semisynthetic lantibiotic NVB333 in vitro and in experimental infection models
}

\begin{abstract}
Steven Boakes ${ }^{1}$, William J Weiss ${ }^{2}$, Mary Vinson ${ }^{1,3}$, Sjoerd Wadman ${ }^{1,4}$ and Michael J Dawson ${ }^{1}$
NVB333 is a novel semisynthetic lantibiotic derived from the amide coupling of 3,5-dichlorobenzylamine to the C-terminal of deoxyactagardine B. The in vitro activity of NVB333 includes efficacy against clinically relevant pathogens including methicillinresistant Staphylococcus aureus and vancomycin-resistant Enterococcus spp. NVB333 shows no cross-resistance with other antibiotics tested and a very low propensity for resistance development. After intravenous dosing NVB333 has high exposure in mouse plasma and shows generally improved in vivo activity compared with vancomycin in mouse infection models despite modest MIC values. In thigh infection models, promising efficacy was demonstrated against several strains of $S$. aureus including methicillin-resistant $S$. aureus (MRSA) and vancomycin-intermediate $S$. aureus (VISA) strains, and against Enterococcus faecalis UNT126-3. Area under the concentration curve (AUC)/MIC was shown to be the best predictor of efficacy against $S$. aureus UNT103-3 with an AUC/MIC of 138 (uncorrected for protein binding) achieving a static effect. NVB333 was also effective in a disseminated infection model where it conferred complete survival from the MRSA strain ATCC 33591 . NVB333 showed rather modest lung penetration after intravenous dosing (AUC in lung $2-3 \%$ of plasma $A U C$ ), but because of very high plasma exposure, therapeutic levels of compound were achieved in the lung. Efficacy at least equal to vancomycin was demonstrated against an MRSA strain (UNT084-3) in a bronchoalveolar infection model. The impressive in vivo efficacy of NVB333 and strong resistance prognosis makes this compound an interesting candidate for development for treating systemic Gram-positive infections. The Journal of Antibiotics (2016) 69, 850-857; doi:10.1038/ja.2016.47; published online 18 May 2016
\end{abstract}

\section{INTRODUCTION}

A recent report by the World Health Organization ${ }^{1}$ has further highlighted the increasing urgency to find a solution to the global problem of a dwindling antimicrobial armamentarium in the face of increasing prevalence of resistance to antibiotics. Estimates suggest that without new antibiotics, by 2050 global annual mortality rates could rise from current levels of $\sim 700000$ to 10 million as a result of the widening spread of antimicrobial resistance. ${ }^{2}$ In addition to the implications to health, the global economic impact of increasing resistance could be up to 100 trillion US dollars by $2050 .^{2}$ Gram-positive bacteria including methicillin-resistant Staphylococcus aureus (MRSA) and Enterococcus spp. are among the main protagonists.

The launch of government initiatives such as GAIN (Generating Antibiotics Incentives Now; Food and Drug Administration (FDA) Safety and Innovation Act, 2012) may have helped stimulate recent FDA approvals for antibiotics (4 approved in $2014^{3}$ compared with 22 from 2000 to the end of $2012^{4}$ ); nevertheless, there remains a real dearth of agents from new classes offering novel mechanisms of action and the potential for reduced resistance development. Although alternative approaches to antibiotics in the treatment of bacterial infections are gaining momentum, ${ }^{5}$ the search for new improved antibiotics remains an important area of exploration. Antimicrobial peptides including lantibiotics represent a largely untapped potential source of antibiotics that crucially may offer a promising resistance prognosis.

Lantibiotics are ribosomally synthesized post-translationally modified peptides that have encouraging activity predominantly against clinically important Gram-positive pathogens. ${ }^{6}$ The type B lantibiotics that include mersacidin, actagardine and deoxyactagardine $\mathrm{B}\left(\mathrm{DAB}^{7}\right)$ are globular and exert their antibacterial effect by inhibition of cell wall biosynthesis. ${ }^{8}$ Lipid II is not the product of a single gene but derived from multiple enzyme-catalyzed reactions, and as such agents targeting lipid II have a reduced propensity for resistance development as recently described for the antibacterial teixobactin. ${ }^{9}$ Unlike glycopeptides these lantibiotics do not bind to the D-Ala-D-Ala motif of lipid II, but to the pyrophosphate-sugar moiety. ${ }^{10}$ Importantly this alternative target site reduces the chance of cross-resistance with

${ }^{1}$ Novacta Biosystems and Cantab Anti-infectives, BioPark, Welwyn Garden City, Hertfordshire, UK and ${ }^{2}$ University of North Texas Health Science Center, Fort Worth, TX, USA ${ }^{3}$ Current address: Autolus Ltd, White City, London W12 7RP, UK.

${ }^{4}$ Current address: Lanthio Pharma, Rozenburglaan 13B, 9727 DL Groningen, The Netherlands.

Correspondence: Dr S Boakes, Cantab Anti-infectives, BioPark, Welwyn Garden City, Hertfordshire AL7 3AX, UK.

E-mail: steve.boakes@cantabanti.com

Received 27 November 2015; revised 26 February 2016; accepted 3 April 2016; published online 18 May 2016 
vancomycin-resistant organisms and increases the attractiveness of lantibiotics as medically useful molecules.

To date, only three lantibiotics, NAI-107, ${ }^{11}$ Mu1140 ${ }^{12}$ and NVB302, ${ }^{13}$ have advanced through formal preclinical development and/or clinical trials as antibacterial agents. We report here the evaluation of NVB333, a novel semisynthetic lantibiotic, for efficacy in mouse thigh, lung and disseminated infection models with clinically relevant pathogens. Vancomycin has been included as a comparator alongside NVB333 as it remains the most commonly used narrow spectrum agent to treat Gram-positive infections.

\section{MATERIALS AND METHODS}

\section{Bacterial strains and antibacterials}

The bacterial strains used in the in vitro determination of MICs were collected from global surveillance studies (Eurofins Medinet, Chantilly, VA, USA) and were selected to be representative of those encountered clinically in the United States and Europe. These strains also included resistant populations (for example, daptomycin and linezolid nonsusceptible isolates) of staphylococci and enterococci. Infections were established in in vivo models using bacteria sourced from the American Type Culture Collection (ATCC, Manassas, VA, USA) or from the University of North Texas Health Science Center (UNTHSC, Fort Worth, TX, USA; UNT prefix). These strains included MRSA strains with MIC values that represent the $\operatorname{MIC}_{50}\left(4 \mathrm{mgl}^{-1}\right)$ and $\operatorname{MIC}_{90}\left(8 \mathrm{mgl}^{-1}\right)$ values determined for NVB333. The $S$. aureus isolates UNT084-3 and UNT103-3 are both USA100 MRSA genotype, whereas UNT107-3 and UNT108-3 are vancomycin-intermediate $S$. aureus (VISA; MIC vancomycin 4-8 $\mathrm{mgl}^{-1}$ ) isolates. UNT126-1 is a vancomycin-resistant Enterococcus faecalis (MIC vancomycin $>8 \mathrm{mg} \mathrm{l}^{-1}$ ).

NVB333 is the C-terminal 3,5-dichlorobenzylamine monocarboxamide derivative of the natural product $\mathrm{DAB}$ that was isolated from fermentation broth of the actinomycete Actinoplanes liguriae. ${ }^{7}$ The N-methyl-D-glucamine salt form of NVB333 was supplied by Novacta Biosystems (Welwyn Garden City, UK) and used for all studies. This salt form is soluble in water at a concentration of at least $50 \mathrm{mg} \mathrm{ml}^{-1}$. It was dissolved in $5 \%$ sorbitol and $\mathrm{pH}$ adjusted to $\mathrm{pH} 8.0$ to 8.5 with $\mathrm{HCl}$ for dosing in the thigh and lung infection models. Vancomycin was from commercial sources and prepared in saline for thigh and lung infection studies. Both NVB333 and vancomycin were prepared in $15 \%$ 2-hydroxypropyl- $\beta$-cyclodextrin/4.4\% glucose $/ 0.5 \mathrm{mM} \mathrm{KH}_{2} \mathrm{PO}_{4}$, $\mathrm{pH} 5.0$, for the disseminated infection study.

\section{In vitro methods}

MICs were determined by microbroth dilution using cation-adjusted MuellerHinton broth in 96-well microtiter plates according to Clinical and Laboratory Standards Institute (CLSI) guidelines. ${ }^{14}$

\section{Animals}

Female specific-pathogen-free CD-1 mice were used in thigh and lung infection models, whereas male CD-1 mice were used in the disseminated infection model. All mice weighed $\sim 22 \pm 2 \mathrm{~g}$. For thigh and lung models, neutropenia was induced by i.p. injection of cyclophosphamide at $150 \mathrm{mg} \mathrm{kg}^{-1} 4$ days before infection and $100 \mathrm{mg} \mathrm{kg}^{-1} 1$ day before infection. Previous studies have shown that this produces neutropenia in this model for 5 days. ${ }^{15}$ All animal studies were performed with local ethical committee clearance following protocols approved by the institutional animal care and use committee.

\section{Disseminated infection model}

Groups of six mice (immunocompetent) were inoculated i.p. with S. aureus MRSA ATCC $33591\left(1.1 \times 10^{7}\right.$ CFUs per mouse $)$ suspended in $0.5 \mathrm{ml}$ of Brain Heart Infusion Broth (Oxoid, Basingstoke, UK) with $5 \%$ mucin. ${ }^{16}$ Test substances were administered s.c. at doses of $1,3,5,10$ and $20 \mathrm{mg} \mathrm{kg}^{-1}$ immediately after bacterial challenge and then at 2 and $24 \mathrm{~h}$ after infection. A control group of infected mice was dosed in parallel receiving vehicle only. All 6 of the animals from this group had died within $48 \mathrm{~h}$ of infection. Mortality was recorded once daily for 7 days and the $\mathrm{ED}_{50}$ determined at the end of the 7-day period by nonlinear regression using GraphPad Prism (GraphPad software, La Jolla, CA, USA)

\section{Mouse thigh infection model}

Neutropenic mice were infected by i.m. injection into the right lateral thigh muscle. Each thigh received $\sim 1 \times 10^{5}$ CFUs $(0.1 \mathrm{ml}$ per thigh). Groups of 5 mice were administered test article by i.v. injection at 2 and $14 \mathrm{~h}$ after infection. At $2 \mathrm{~h}$ after infection, a control group of animals was humanely killed using $\mathrm{CO}_{2}$ inhalation to provide a pretreatment control group (start group). At $26 \mathrm{~h}$ after infection, all remaining groups were humanely killed by $\mathrm{CO}_{2}$ inhalation. The right thigh muscle from each animal was removed and homogenized in ice-cold sterile phosphate-buffered saline, $\mathrm{pH}$ 7.4, using a Polytron tissue homogenizer (Kinematica AG, Lucerne, Switzerland). The homogenates were then quantitatively cultured onto Brain Heart Infusion agar (Oxoid) including $0.5 \%$ charcoal $(\mathrm{w} / \mathrm{v})$ and incubated at $37^{\circ} \mathrm{C}$ for $18-24 \mathrm{~h}$ before colonies were enumerated. ${ }^{17}$

\section{Mouse lung infection model}

Groups of five anesthetized (i.p. injection of $40 \mathrm{mg} \mathrm{kg}^{-1}$ ketamine $/ 6 \mathrm{mg} \mathrm{kg}^{-1}$ xylazine mixture) neutropenic mice per treatment were infected by i.n. instillation of $50 \mu$ inoculum into each nostril (5.62 $\log _{10}$ CFUs per mouse) and kept in an upright position for $\sim 10 \mathrm{~min}$ after infection. Test agents were administered by i.v. injection at 2 and $14 \mathrm{~h}$ (b.i.d.) after infection. At $2 \mathrm{~h}$ after infection, a control group of animals was humanely killed by $\mathrm{CO}_{2}$ inhalation (start group). All remaining animals were killed in the same manner at $26 \mathrm{~h}$ after infection, including a group that had received vehicle only (end group). Lungs were aseptically removed and then homogenized and colonies enumerated per lung pair by plating dilutions onto Brain Heart Infusion agar including $0.5 \%$ charcoal $(\mathrm{w} / \mathrm{v})$. Plates were incubated at $37^{\circ} \mathrm{C}$ overnight $(\sim 16-20 \mathrm{~h})$ before colonies were enumerated.

\section{Mouse lung pharmacokinetics}

The levels of NVB333 in both plasma and epithelial lining fluid (ELF) were determined in neutropenic mice infected by i.n. instillation using an inoculum of $5 \log _{10}$ CFU MRSA UNT084-3. At $2 \mathrm{~h}$ after infection, NVB333 was administered i.v. at dose levels of 25 and $80 \mathrm{mg} \mathrm{kg}^{-1}$. Before dosing and then at $0.083,0.25,0.5,1,2,4$ and $8 \mathrm{~h}$ after dosing, groups of three mice per timepoint were killed by $\mathrm{CO}_{2}$ inhalation and blood collected by cardiac puncture. ELF was recovered from the lungs of each animal by washing up to three times (bronchoalveolar lavage) with $1 \mathrm{ml}$ sterile saline using a $1 \mathrm{ml}$ tuberculin syringe. The levels of NVB333 in both plasma and ELF were determined by LC-MS. Urea concentrations in both the blood and ELF samples were determined using a Quantichrom Urea Assay Kit (Bioassay Systems, Hayward, CA, USA) to ascertain the dilution factor of the ELF during the saline washes. Concentrations of NVB333 in the ELF were calculated using the formula; $\mathrm{ELF}$ concentration $=(\mathrm{AC} \times \mathrm{BU}) / \mathrm{LU}$, where $\mathrm{AC}$ is the antibiotic concentration in the bronchoalveolar lavage, $\mathrm{BU}$ is the blood urea concentration and LU is the lavage fluid urea concentration. An additional set of infected animals was killed and lungs removed to verify the level of bacterial titers at 2 and $8 \mathrm{~h}$ after infection

\section{Pharmacokinetic/pharmacodynamic (PK/PD) relationship of NVB333}

The PK/PD relationship for NVB333 was investigated using the mouse thigh infection model and the MRSA strain UNT103-3.

Single-dose pharmacokinetics of NVB333 were determined in thigh-infected mice at dose levels of 5, 10,25, 50 and $80 \mathrm{mg} \mathrm{kg}^{-1}$. At $2 \mathrm{~h}$ after infection, mice received NVB333 by s.c. administration, and then at $0.083,0.25,0.5,1,2,4,8$ and $24 \mathrm{~h}$ after drug administration, groups of 3 animals for each dose level were killed. Blood was collected by cardiac puncture and allowed to clot on ice. Serum was separated from the clot by centrifugation and the concentration of NVB333 determined by LC-MS. The PK parameters were determined by noncompartmental methods using PK Solutions 2.0 (Summit Research Services, Montrose, CO, USA).

Dose range studies for NVB333 were followed by dose fractionation studies. NVB333 was administered as a single s.c. dose at levels of $1,5,10,20,25,40$, 
50,80 and $100 \mathrm{mg} \mathrm{kg}^{-1}$ into thigh-infected mice at $2 \mathrm{~h}$ after infection. At $26 \mathrm{~h}$, the mice were killed and the thighs removed and bacterial counts enumerated as described earlier. Total dose levels of $5,10,15,20,30,50,80$ and $100 \mathrm{mg} \mathrm{kg}^{-1}$ were subsequently administered as fractionated doses over a 24-h period to infected mice beginning $2 \mathrm{~h}$ after infection. The dose levels were administered as either single injections, two equally divided doses given $12 \mathrm{~h}$ apart or four equally divided doses given $6 \mathrm{~h}$ apart. At $26 \mathrm{~h}$ after infection, thighs were removed and bacterial counts enumerated as before. A sigmoid dose-response model derived from the four-parameter Hill equation was used to calculate the respective relationship that produced a net bacteriostatic effect and a $1 \log _{10}$ kill over $24 \mathrm{~h}$ (static and $1 \log$ efficacy).

\section{Sample and statistical analysis}

Plasma samples were prepared for analysis by LC-MS by adding $150 \mu \mathrm{l}$ of acetonitrile containing $0.1 \%(\mathrm{v} / \mathrm{v})$ formic acid to $50 \mu \mathrm{l}$ of plasma and mixing. Supernatant $(75 \mu \mathrm{l})$ was then diluted with $150 \mu \mathrm{l}$ of water before analysis. Samples $(10 \mu \mathrm{l})$ were injected onto a Synergi Polar-RP column $(2.5 \mu \mathrm{m}$ $50 \times 2.0 \mathrm{~mm}$ ) on an Agilent G1312B HPLC linked to an Agilent 6410 mass spectrometer (Santa Clara, CA, USA). A gradient of 5 to $95 \%$ acetonitrile $(0.1 \%$ formic acid) over $5 \mathrm{~min}$ was used with a flow rate of $0.5 \mathrm{ml} \mathrm{min}^{-1}$.

Counts of bacterial colonies recovered from homogenized tissue from efficacy studies were compared by one-way analysis of variance and Dunnett's multiple comparison test against the end control using GraphPad Prism version 6.05. No significant difference between groups: ${ }^{\star} P<0.05$.

\section{RESULTS}

In vitro antibacterial activity

The MICs of NVB333 and vancomycin were determined against a panel of organisms that consist of a representative population of recent clinical isolates of Gram-positive pathogens and are presented in Table 1. The MIC values for NVB333 against vancomycin-susceptible strains were generally at least fourfold higher than for vancomycin. An exception was Streptococcus pyogenes against which NVB333 had an MIC $_{90}$ of $\leqslant 0.125 \mathrm{mg} \mathrm{l}^{-1}$ compared with $0.5 \mathrm{mg} \mathrm{l}^{-1}$ for vancomycin, although it should be noted that a small number of strains had MIC values for NVB333 as high as $4 \mathrm{mgl}^{-1}$.

It was notable that MIC values for NVB333 were unaffected by resistance to vancomycin and linezolid, although a slight $(2 \times)$ elevation of MIC value was observed for VISA and daptomycin resistant strains. This 'nonspecific' MIC elevation is common to cell wall-active antibiotics. ${ }^{18}$

\section{Disseminated lethal infection model}

As an initial indication of the efficacy of NVB333 in protecting mice from a disseminated infection, NVB333 was administered to groups of six mice infected with $S$. aureus ATCC 33591. The MIC of NVB333 against this MRSA strain was $2 \mathrm{mgl}^{-1}$, and this is below the $\mathrm{MIC}_{50}$

Table 1 Summary of the MIC values ( $\mathrm{mg} \mathrm{I}^{-1}$ ) of NVB333 and vancomycin against a panel of Gram-positive pathogens

\begin{tabular}{|c|c|c|c|c|c|c|c|}
\hline Organism & Compound & Phenotype & $\mathrm{N}$ & Range & Mode & $M I C_{50}$ & $M I C_{90}$ \\
\hline \multirow[t]{14}{*}{ S. aureus } & \multirow[t]{7}{*}{ NVB333 } & All & 248 & $4-16$ & 4 & 4 & 8 \\
\hline & & MSSA & 94 & $4-8$ & 4 & 4 & 8 \\
\hline & & MRSA & 104 & $4-8$ & 4 & 4 & 8 \\
\hline & & Daptomycin ${ }^{\mathrm{R}}$ & 10 & $4-8$ & 8 & 8 & 8 \\
\hline & & Linezolid $^{R}$ & 10 & $4-8$ & $4-8$ & 4 & 8 \\
\hline & & VISA & 10 & $4-16$ & 8 & 8 & 16 \\
\hline & & VRSA & 6 & $4-8$ & $4-8$ & NA & NA \\
\hline & \multirow[t]{7}{*}{ Vancomycin } & All & 248 & $0.25->64$ & 1 & 1 & 2 \\
\hline & & MSSA & 94 & $0.5-2$ & 1 & 1 & 1 \\
\hline & & MRSA & 104 & $0.25-2$ & 1 & 1 & 1 \\
\hline & & Daptomycin $^{R}$ & 10 & $1-4$ & 2 & 2 & 2 \\
\hline & & Linezolid $^{\mathrm{R}}$ & 10 & $1-2$ & 1 & 1 & 2 \\
\hline & & VISA & 10 & $1->64$ & 4 & 4 & 4 \\
\hline & & VRSA & 6 & $>64$ & $>64$ & NA & NA \\
\hline \multirow[t]{6}{*}{ E. faecalis } & \multirow[t]{3}{*}{ NVB333 } & All & 43 & $2-8$ & 4 & 4 & 4 \\
\hline & & VSE & 40 & $1-16$ & 4 & 4 & 16 \\
\hline & & VRE & 3 & $2-16$ & 8 & NA & NA \\
\hline & \multirow[t]{3}{*}{ Vancomycin } & All & 42 & $0.5->64$ & 1 & 1 & 2 \\
\hline & & VSE & 40 & $0.5-4$ & 1 & 1 & 2 \\
\hline & & VRE & 3 & $32->64$ & $>64$ & NA & NA \\
\hline \multirow[t]{6}{*}{ E. faecium } & \multirow[t]{3}{*}{ NVB333 } & All & 57 & $1-16$ & 8 & 8 & 16 \\
\hline & & VSE & 28 & $1-16$ & 4 & 4 & 16 \\
\hline & & VRE & 29 & $2-16$ & 8 & 8 & 8 \\
\hline & \multirow[t]{3}{*}{ Vancomycin } & All & 57 & $0.5->64$ & $>64$ & 32 & $>64$ \\
\hline & & VSE & 28 & $0.5-4$ & 1 & 1 & 2 \\
\hline & & VRE & 29 & $32->64$ & $>64$ & $>64$ & $>64$ \\
\hline \multirow[t]{2}{*}{ S. pneumoniae } & NVB333 & All & 50 & $\leqslant 0.12-4$ & 4 & 2 & 4 \\
\hline & Vancomycin & All & 50 & $0.25-0.5$ & 0.5 & 0.5 & 0.5 \\
\hline \multirow[t]{2}{*}{ S. pyogenes } & NVB333 & All & 50 & $\leqslant 0.12-4$ & $\leqslant 0.12$ & $\leqslant 0.12$ & 0.5 \\
\hline & Vancomycin & All & 50 & $0.25-1$ & 0.5 & 0.5 & 0.5 \\
\hline \multirow[t]{2}{*}{ S. agalactiae } & NVB333 & All & 30 & $0.5-16$ & 8 & 8 & 8 \\
\hline & Vancomycin & All & 30 & $0.25-1$ & 0.5 & 0.5 & 0.5 \\
\hline Viridans group & NVB333 & All & 20 & $\leqslant 0.12-8$ & 4 & 2 & 4 \\
\hline streptococci & Vancomycin & All & 20 & $0.06-1$ & 0.5 & 0.5 & 1 \\
\hline
\end{tabular}

Abbreviations: MRSA, methicillin-resistant Staphylococcus aureus; MSSA, methicillin-sensitive Staphylococcus aureus; NA, not achieved or not applicable; VISA, vancomycin-intermediate Staphylococcus aureus; VRSA, vancomycin-resistant Staphylococcus aureus; VRE, vancomycin-resistant enterococcus; VSE, vancomycin-sensitive enterococcus. Superscript 'R' denotes resistant phenotype. 
value determined for NVB333. Infected mice received NVB333 or vancomycin as a comparator delivered s.c. immediately before infection and then at 2 and $24 \mathrm{~h}$ after infection and mortality was then recorded once daily for 7 days. At the end of this period, the $\mathrm{ED}_{50}$ values or concentrations required to achieve $50 \%$ survival compared with the vehicle control were determined for NVB333 and vancomycin as 1 and $3 \mathrm{mg} \mathrm{kg}^{-1}$, respectively.

Efficacy against $S$. aureus infection in the neutropenic mouse thigh infection model

In order to investigate more quantitatively the efficacy of i.v. NVB333, NVB333 was administered i.v. in a series of neutropenic mouse thigh infection studies where groups of five mice had been infected with one of four strains of $S$. aureus. Vancomycin, which is commonly used to treat systemic Gram-positive infections, was dosed alongside NVB333 as a comparator. The test agents were dosed i.v. as this is the most direct route of administration and removes the risk that comparisons between compounds will be compromised by differences in release kinetics from a s.c. compartment.

The strains used in these studies demonstrated different levels of in vitro susceptibility to NVB333 and vancomycin. The MIC of NVB333 against the MRSA strain ATCC 33591 was $2 \mathrm{mgl}^{-1}$; the other strains that were evaluated in the infection models were the MRSA strain UNT103-3 for which the MIC of NVB333 was $4 \mathrm{mgl}^{-1}$, equivalent to the $\mathrm{MIC}_{50}$ for $\mathrm{NVB} 333$, and the two VISA strains UNT107-3 and UNT108-3 for which the MIC of NVB333 was $8 \mathrm{mgl}^{-1}$, equivalent to the $\mathrm{MIC}_{90}$ for NVB333. The MIC for vancomycin was $4 \mathrm{mgl}^{-1}$ against the VISA strains and $1 \mathrm{mgl}^{-1}$ for all other strains. The effect of i.v. administration of NVB333 and vancomycin on the bacterial burden of neutropenic CD-1 mice infected in the lateral thigh muscle with these strains of $S$. aureus is shown in Figure 1.

Thigh infection was established with all four isolates with the $2 \mathrm{~h}$ control groups (start) having a bacterial burden of $\sim 5 \log _{10}$ CFU/ thigh that increased to between 7 and $9 \log _{10} \mathrm{CFU} /$ thigh after $26 \mathrm{~h}$ (end) in the untreated controls. In all studies, both NVB333 and vancomycin were administered i.v. at 2 and $14 \mathrm{~h}$ after infection, with harvest of the thigh tissue at $26 \mathrm{~h}$ after infection.

Both NVB333 and vancomycin showed a dose-dependent reduction in counts. The dose required to achieve the static dose and $1 \log _{10}$ CFU reduction below the static dose is shown in Table 2. As expected for NVB333, this dose tended to increase with the MIC of the strain.

Efficacy against E. faecalis (vancomycin-resistant enterococcus) infection in the neutropenic mouse thigh infection model The efficacy of NVB333 was also evaluated against $E$. faecalis UNT126-1. This strain of $E$. faecalis is vancomycin resistant (MIC $>8 \mathrm{mgl}^{-1}$ ), with the MIC of NVB333 being $4 \mathrm{mgl}^{-1}$. Both NVB333 and
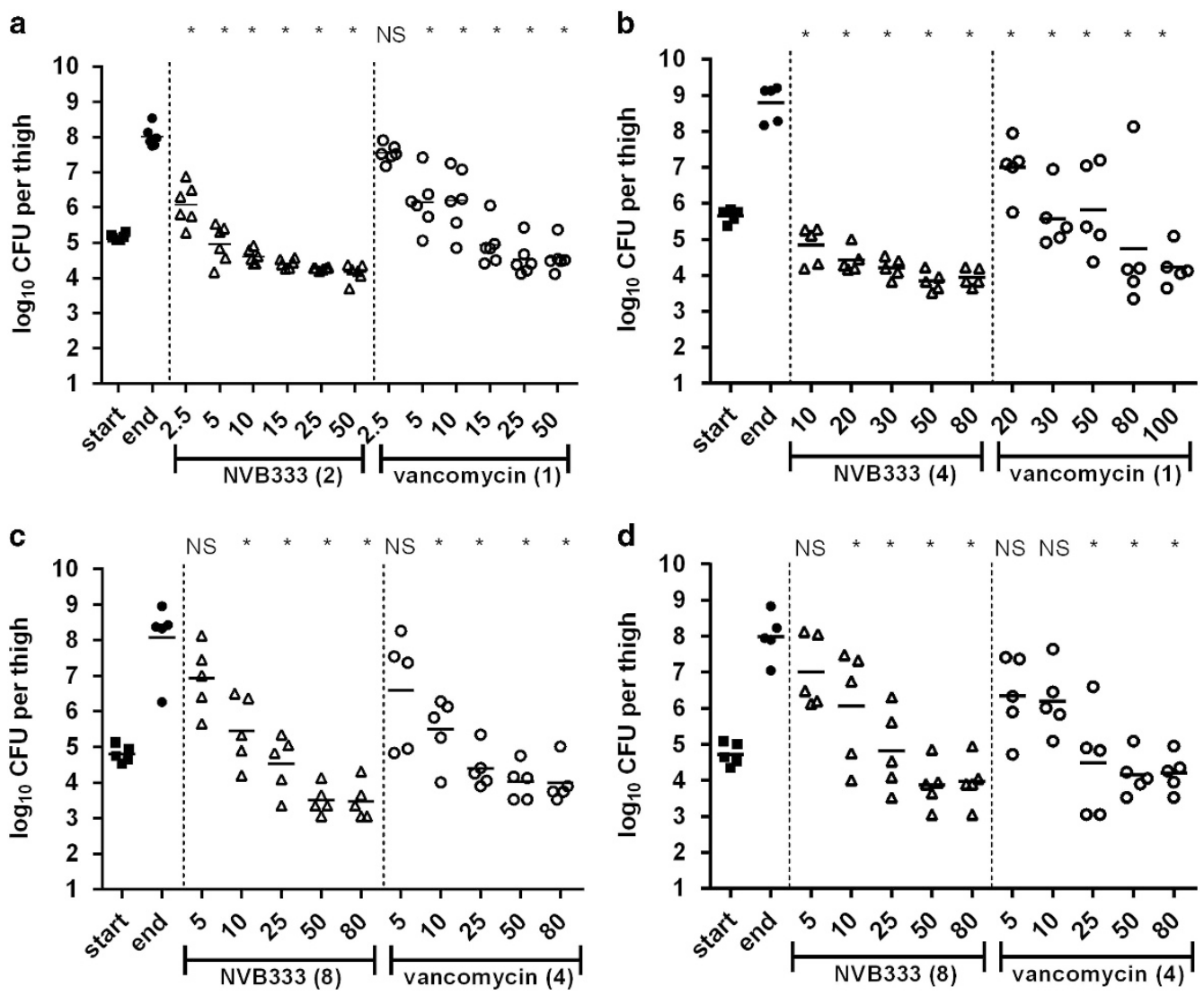

Figure 1 Efficacies of NVB333 and vancomycin in mouse thigh models with infection caused by different strains of Staphylococcus aureus. (a) methicillinresistant Staphylococcus aureus (MRSA) ATCC 33591, (b) MRSA UNT103-3, (c) vancomycin-intermediate Staphylococcus aureus (VISA) UNT107-3 and (d) VISA UNT108-3. Treatment groups represent $\mathrm{mg} \mathrm{kg}^{-1}$ delivered i.v. at 2 and $14 \mathrm{~h}$ after infection with harvest at $26 \mathrm{~h}$ after infection. Each symbol represents the datum from a single thigh with horizontal bars denoting mean values. Respective MIC values (mg I-1) are shown in brackets. The 'start' group shows the levels of bacterial burden at the first dosing timepoint, whereas the bacterial burdens of a control group receiving vehicle only at the end of the study are represented by the 'end' group. Counts from each dose group of NVB333 and vancomycin were compared by one-way analysis of variance (ANOVA) followed by Dunnett's comparison test against the $26 \mathrm{~h}$ control (end). NS, no significant difference between groups; ${ }^{*} P<0.05$. 
Table 2 Summary of the total daily doses of NVB333 and vancomycin in mouse infection models of Gram-positive pathogens required to reduce the bacterial burden to the static level, $1 \log _{10}$ reduction from the static level and $1 \log _{10}$ reduction from the $24 \mathrm{~h}$ level (lung model only)

\begin{tabular}{|c|c|c|c|c|c|}
\hline \multirow[b]{2}{*}{ Model (drug route) } & \multirow[b]{2}{*}{ Microorganism } & \multirow[b]{2}{*}{ Compound } & \multirow[b]{2}{*}{$M I C\left(m g I^{-1}\right)$} & \multicolumn{2}{|c|}{ Total daily dose $\left(m g \mathrm{~kg}^{-1}\right)$} \\
\hline & & & & Static effect/ED 50 & 1-log drop \\
\hline \multirow[t]{2}{*}{ Mouse thigh (i.v.) } & \multirow[t]{2}{*}{ MRSA ATCC 33591} & NVB333 & 2 & 10 & 100 \\
\hline & & Vancomycin & 1 & 30 & NA \\
\hline \multirow[t]{2}{*}{ Mouse thigh (i.v.) } & \multirow[t]{2}{*}{ MRSA UNT103-3 } & NVB333 & 4 & $\leqslant 20$ & 40 \\
\hline & & Vancomycin & 1 & 60 & $160-200^{a}$ \\
\hline \multirow[t]{2}{*}{ Mouse thigh (i.v.) } & \multirow[t]{2}{*}{ VISA UNT107-3 } & NVB333 & 8 & 50 & 100 \\
\hline & & Vancomycin & 4 & 50 & NA \\
\hline \multirow[t]{2}{*}{ Mouse thigh (i.v.) } & \multirow[t]{2}{*}{ VISA UNT108-3 } & NVB333 & 8 & 50 & NA \\
\hline & & Vancomycin & 4 & 50 & NA \\
\hline \multirow[t]{2}{*}{ Mouse thigh (i.v.) } & \multirow[t]{2}{*}{ E. faecalis UNT126-3 } & NVB333 & 4 & $\leqslant 20$ & 40 \\
\hline & & Vancomycin & $>8$ & 40 & NA \\
\hline \multirow[t]{2}{*}{ Mouse lung (i.v.) } & \multirow[t]{2}{*}{ MRSA UNT084-3 } & NVB333 & 4 & NA & $50-100^{b}$ \\
\hline & & Vancomycin & 1 & NA & NA \\
\hline \multirow{2}{*}{$\begin{array}{l}\text { Mouse disseminated } \\
\text { infection (s.c.) }\end{array}$} & \multirow[t]{2}{*}{ MRSA ATCC 33591} & NVB333 & 2 & 3 & NA \\
\hline & & Vancomycin & 1 & 9 & NA \\
\hline
\end{tabular}

Abbreviations: MRSA, methicillin-resistant Staphylococcus aureus; NA, not achieved at the dose levels tested or not applicable (disseminated infection model); VISA, vancomycin-intermediate Staphylococcus aureus.

The $\mathrm{ED}_{50}$ is presented for the disseminated infection study.

The $\mathrm{ED}_{50}$ is presented for the disseminated infection study.
${ }^{0} 0.92 \log _{10}$ reduction at $160 \mathrm{mg} \mathrm{kg}^{-1}(2 \times 80 \mathrm{mg} \mathrm{kg})$ and $1.42 \log _{10}$ reduction at $200 \mathrm{mg} \mathrm{kg}^{-1}\left(2 \times 100 \mathrm{mg} \mathrm{kg}^{-1}\right)$.

${ }^{b} 0.94 \log _{10}$ reduction at $50 \mathrm{mg} \mathrm{kg}^{-1}\left(2 \times 25 \mathrm{mg} \mathrm{kg}^{-1}\right)$ and $1.04 \log _{10}$ reduction at $100 \mathrm{mg} \mathrm{kg}^{-1}\left(2 \times 50 \mathrm{mg} \mathrm{kg}^{-1}\right)$.

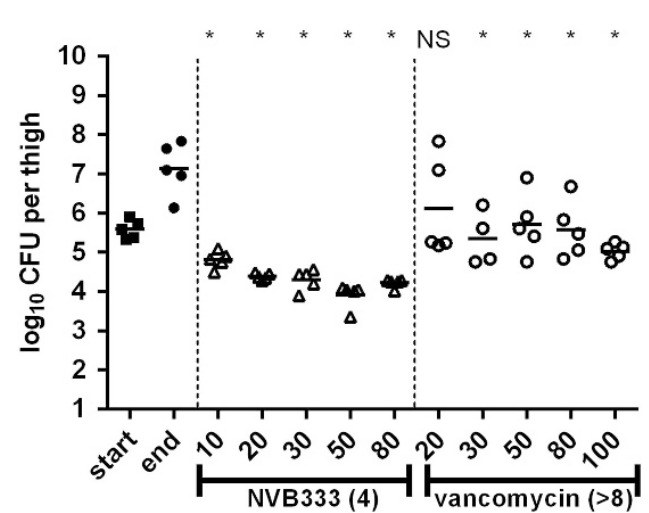

Figure 2 Effectiveness of NVB333 and vancomycin in a mouse thigh model with infection caused by vancomycin-resistant Enterococcus faecalis UNT126-3. Treatment groups represent $\mathrm{mg} \mathrm{kg}^{-1}$ delivered i.v. at 2 and $14 \mathrm{~h}$ after infection with harvest at $26 \mathrm{~h}$ after infection. Each symbol represents the datum from a single thigh with horizontal bars representing mean values. Respective MIC values $\left(\mathrm{mgl}^{-1}\right)$ are shown in brackets. The 'start' group shows the levels of bacterial burden at the first dosing timepoint, whereas the bacterial burdens of a control group receiving vehicle only at the end of the study are represented by the 'end' group. Counts from each dose group of NVB333 and vancomycin were compared by one-way analysis of variance (ANOVA) followed by Dunnett's comparison test against the $26 \mathrm{~h}$ control (end). NS, no significant difference between groups; ${ }^{*} P<0.05$.

vancomycin were administered i.v. at 2 and $14 \mathrm{~h}$ after infection with harvest of the thigh tissue at $26 \mathrm{~h}$ after infection. The mean bacterial burdens of the control and treatment groups are shown in Figure 2. The start and end control groups had bacterial burdens of 5.58 and $7.13 \log _{10} \mathrm{CFU} /$ thigh, respectively.

The lowest dose of NVB333 tested $\left(10 \mathrm{mg} \mathrm{kg}^{-1} \times 2\right)$ caused a reduction in counts below the static level. Vancomycin appeared to be borderline for efficacy with $100 \mathrm{mg} \mathrm{kg}^{-1} \times 2$ needed to show a comparable effect. The reduction in bacterial burden of this strain of $E$. faecalis in the thigh model was comparable to the response of the MRSA strain for which the MIC of NVB333 is the same (Table 2).

\section{Mouse lung infection model}

The efficacy of NVB333 and vancomycin was determined in a mouse lung infection model with compounds delivered i.v. at 2 and $14 \mathrm{~h}$ after infection with harvest of the lung tissue at $26 \mathrm{~h}$ after infection. In this model the S. aureus MRSA UNT084-3 strain was used to establish an infection in the lungs. The bacterial burden of the control group at the first dosing timepoint ( $2 \mathrm{~h}$ after infection) was $7.23 \log _{10}$ CFUs. This had increased to $8.83 \log _{10}$ CFUs in the $26 \mathrm{~h}$ control (end) group. The i.v. administration of NVB333 at dose levels of 10 to $80 \mathrm{mg} \mathrm{kg}^{-1}$ resulted in a maximum reduction in bacterial burden of $1.59 \log _{10}$ CFUs compared with the $26 \mathrm{~h}$ control group that was close to a static effect. The response to the administration of vancomycin across the dose levels was less marked with a maximum reduction in bacterial burden of $0.25 \log _{10}$ CFUs at $80 \mathrm{mg} \mathrm{kg}^{-1}$ compared with the vehicle control. The reduction in bacterial burdens across the complete range of dose levels is shown in Figure 3, and the dose levels required to reach $1 \log _{10}$ reduction below the $24 \mathrm{~h}$ control (end) are shown in Table 2.

The PK of NVB333 in the plasma and ELF were determined using a separate cohort of infected mice. NVB333 was administered i.v. at single dose levels of 25 and $80 \mathrm{mg} \mathrm{kg}^{-1} 2 \mathrm{~h}$ after infection and plasma and ELF were collected at 7 timepoints to $8 \mathrm{~h}$ after dosing. The PK parameters determined from measurements of total amounts of NVB333 in the plasma and ELF are shown in Table 3. Overall, plasma exposure (area under the concentration curve (AUC)) was dose proportional with an AUCinf of $992.3 \mu \mathrm{g} \mathrm{h} \mathrm{ml}^{-1}$ at $25 \mathrm{mg} \mathrm{kg}^{-1}$ and $3101 \mu \mathrm{g} \mathrm{m}^{-1}$ at $80 \mathrm{mg} \mathrm{kg}^{-1}$. The plasma half-life of 3.2 and $3.3 \mathrm{~h}$, clearance values of 25.2 and $25.8 \mathrm{ml} \mathrm{h}^{-1} \mathrm{~kg}^{-1}$ and volume of distribution of 115.3 and $123.7 \mathrm{ml} \mathrm{kg}^{-1}$ were comparable for the 25 and $80 \mathrm{mg} \mathrm{kg}^{-1}$ doses. Peak ELF levels of NVB333 reached $5.06 \mu \mathrm{g} \mathrm{ml}^{-1}$ at $0.5 \mathrm{~h}$ for the $25 \mathrm{mg} \mathrm{kg}^{-1}$ dose and $15.31 \mu \mathrm{g} \mathrm{ml}^{-1}$ at $2 \mathrm{~h}$ for the $80 \mathrm{mg} \mathrm{kg}^{-1}$ dose. The half-life of NVB333 in the ELF 
appeared to be comparable to plasma (2.1-3.7 h). Total ELF exposure was $33 \mu \mathrm{g} \mathrm{h} \mathrm{m}^{-1}$ at $25 \mathrm{mg} \mathrm{kg}^{-1}$ and $60.3 \mu \mathrm{g} \mathrm{h} \mathrm{ml} \mathrm{g}^{-1}$ at $80 \mathrm{mg} \mathrm{kg}^{-1}$. This represents $\sim 2-3 \%$ penetration into the ELF (based on AUC) as compared with exposure in plasma. The low penetration of NVB333 into the ELF may be a result of high protein binding of NVB333. Despite this the levels of NVB333 in ELF remain above the MIC for substantial periods.

Relationship between PK/PD indices and antibacterial activity in the mouse thigh infection model

The PK/PD relationship of NVB333 in the mouse thigh infection model was determined for S. aureus MRSA UNT103-3. The MIC of NVB333 against this organism was $4 \mathrm{mg} \mathrm{l}^{-1}$, equivalent to the $\mathrm{MIC}_{50}$ for NVB333 against $S$. aureus. In order to facilitate dosing more than three times per day and mitigate issues associated with multiple i.v. dosing of animals in large numbers, NVB333 was dosed s.c. The total

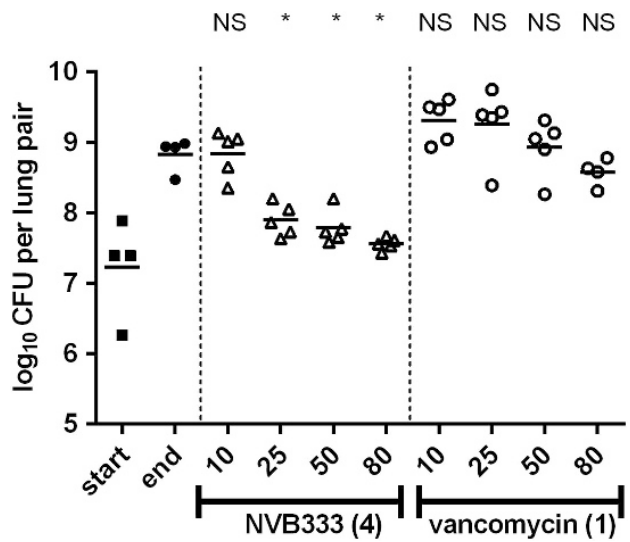

Figure 3 Efficacies of NVB333 and vancomycin in a mouse lung model with infection caused by methicillin-resistant Staphylococcus aureus (MRSA) UNT084-3. Doses were delivered i.v. at 2 and $14 \mathrm{~h}$ after infection with harvest at $26 \mathrm{~h}$ after infection. Each symbol represents the datum from a pair of lungs, with horizontal bars representing mean values. Respective MIC values $\left(\mathrm{mg} \mathrm{l}^{-1}\right)$ are shown in brackets. The 'start' group shows the levels of bacterial burden at the first dosing time point, whereas the bacterial burdens of a control group receiving vehicle only at the end of the study are represented by the 'end' group. Counts from each dose group of NVB333 and vancomycin were compared by one-way analysis of variance (ANOVA) followed by Dunnett's comparison test against the $26 \mathrm{~h}$ control (end). NS, no significant difference between groups; ${ }^{\star} P<0.05$.

Table 3 Summary of the pharmacokinetics of NVB333 in plasma and ELF after i.v. administration at 25 and $80 \mathrm{mg} \mathrm{kg}^{-1}$ to neutropenic mice infected i.n. with $S$. aureus MRSA UNT084-3

\begin{tabular}{|c|c|c|c|c|}
\hline \multirow[b]{2}{*}{ Parameter } & \multicolumn{2}{|c|}{ Plasma } & \multicolumn{2}{|c|}{$E L F$} \\
\hline & $25 \mathrm{mg} \mathrm{kg}^{-1}$ & $80 \mathrm{mg} \mathrm{kg}^{-1}$ & $25 \mathrm{mg} \mathrm{kg}^{-1}$ & $80 \mathrm{mg} \mathrm{kg}^{-1}$ \\
\hline $\mathrm{C}_{\max }\left(\mu \mathrm{g} \mathrm{ml^{-1 }}\right)$ & 349.1 & 521.8 & 5.06 & 15.3 \\
\hline$T_{\max }(h)$ & 0.083 & 0.083 & 0.5 & 2 \\
\hline$T_{1 / 2}(h)$ & 3.2 & 3.3 & 3.7 & 2.1 \\
\hline $\mathrm{AUC}_{0-\mathrm{t}}\left(\mu \mathrm{g} \mathrm{h} \mathrm{ml}^{-1}\right)$ & 885.7 & 2536.6 & 24.9 & 56.8 \\
\hline$A \cup C_{\text {inf }}\left(\mu g \mathrm{~h} \mathrm{ml}^{-1}\right)$ & 992.3 & 3101 & 33 & 60.3 \\
\hline $\mathrm{Cl}\left(\mathrm{ml} \mathrm{h}^{-1} \mathrm{~kg}^{-1}\right)$ & 25.2 & 25.8 & NA & NA \\
\hline $\mathrm{V}_{\mathrm{d}}\left(\mathrm{ml} \mathrm{kg} \mathrm{kg}^{-1}\right)$ & 115.3 & 123.7 & NA & NA \\
\hline
\end{tabular}

Abbreviations: AUC, area under the concentration curve; ELF, epithelial lining fluid; MRSA, methicillin-resistant Staphylococcus aureus; NA, not achieved at the dose levels tested or not applicable. (that is, free plus protein bound) plasma concentrations of NVB333 in neutropenic mice infected in the thigh with $S$. aureus MRSA UNT103-3 as a function of time after single SC doses of NVB333 of $5,10,25,50$ and $80 \mathrm{mg} \mathrm{kg}^{-1}$ are shown in Figure 4. Peak plasma levels of NVB333 dosed s.c. were achieved at 2 to $8 \mathrm{~h}$ after administration. $\mathrm{C}_{\max }$ levels ranged from $17.8 \mu \mathrm{g} \mathrm{ml}^{-1}$ at $5 \mathrm{mg} \mathrm{kg}^{-1}$ to $68.7 \mu \mathrm{g} \mathrm{ml}^{-1}$ at $80 \mathrm{mg} \mathrm{kg}^{-1}$. Total plasma exposure (AUC) was dose proportional with calculated values of $88.7 \mu \mathrm{g} \mathrm{h}^{-1} \mathrm{ml}^{-1}$ at $5 \mathrm{mg} \mathrm{kg}^{-1}$ increasing to $1434.7 \mu \mathrm{g} \mathrm{h}^{-1} \mathrm{ml}^{-1}$ at $80 \mathrm{mg} \mathrm{kg}^{-1}$.

Two dose ranging efficacy studies were then carried out. The first resulted in control counts at $2 \mathrm{~h}$ of $5.75 \pm 0.15 \log _{10}$ CFUs that increased to $7.95 \pm 0.30 \log _{10}$ CFUs at $26 \mathrm{~h}$, whereas the second study exhibited counts of $5.29 \pm 0.83 \log _{10}$ CFUs at $2 \mathrm{~h}$ and $9.02 \pm 0.15 \log _{10}$ CFUs for the $26 \mathrm{~h}$ control. In both studies treatment with NVB333 demonstrated a similar dose response; in the first study the doses of 25 to $100 \mathrm{mg} \mathrm{kg}^{-1}$ resulted in a 2.37 to $3.16 \log _{10}$ CFU reduction from the $26 \mathrm{~h}$ control counts, whereas in the second study doses of 20 to $100 \mathrm{mg} \mathrm{kg}^{-1}$ produced $\log _{10}$ CFU reductions of 1.11 to $3.94 \log _{10}$ CFUs compared with the $26 \mathrm{~h}$ control.

In dose fractionation studies, NVB333 was delivered to infected animals at total doses of 5, 10, 15, 20,30,50, 80 and $100 \mathrm{mg} \mathrm{kg}^{-1}$ administered as a single dose ( $\mathrm{q} 24 \mathrm{~h}) 2 \mathrm{~h}$ after infection or as two equal doses ( $(\mathrm{q} 12 \mathrm{~h}$ ) administered $12 \mathrm{~h}$ apart or four equal doses delivered $6 \mathrm{~h}$ apart (q6h). The dosage required to achieve a reduction of the bacterial burden to the static dose level was 31.8, 25.4 and $38.8 \mathrm{mg} \mathrm{kg}^{-1}$ for the $\mathrm{q} 24 \mathrm{~h}, \mathrm{q} 12 \mathrm{~h}$ and $\mathrm{q} 6 \mathrm{~h}$ regimens, respectively. The $\log _{10}$ CFU counts from the dose fractionation study were plotted against PK/PD parameters of AUC/MIC, $\mathrm{C}_{\max } / \mathrm{MIC}$ and $\% \mathrm{~T}_{24}>\mathrm{MIC}$ and are shown in Figure 5. The PK/PD parameter that correlated closest with efficacy was AUC/MIC with a correlation coefficient of $r^{2}=0.90$, followed by $\mathrm{C}_{\max } / \mathrm{MIC}\left(r^{2}=0.85\right)$ and $\% \mathrm{~T}_{24}>\mathrm{MIC}$ $\left(r^{2}=0.57\right)$. The magnitudes of these parameters required to achieve a static effect in this model were an AUC/MIC of 138, $\mathrm{C}_{\max } / \mathrm{MIC}$ of 8.1 and $\% \mathrm{~T}_{24}>$ MIC of $95.9 \%$. The magnitude required for a $1 \log _{10}$ CFU reduction from the static dose was calculated at 234 for

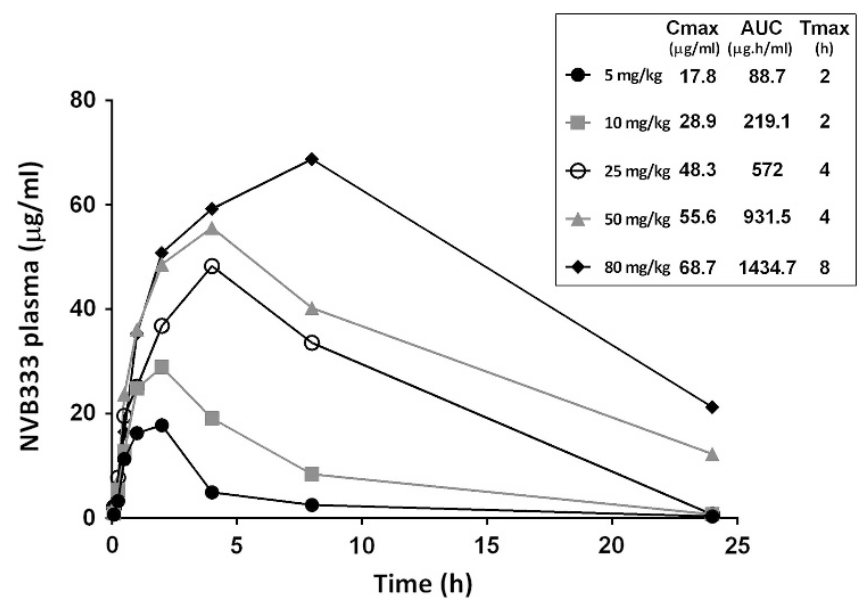

Figure 4 Single-dose pharmacokinetics (PK) of NVB333 in neutropenic mice infected in the thigh with methicillin-resistant Staphylococcus aureus (MRSA) UNT103-3. At $2 \mathrm{~h}$ after infection, mice received NVB333 by s.C. administration at dose levels of $5,10,25,50$ and $80 \mathrm{mg} \mathrm{kg}^{-1}$, and then at $0.083,0.25,0.5,1,2,4,8$ and $24 \mathrm{~h}$ after drug administration, groups of 3 animals for each dose level were killed. Each symbol represents the mean value from three animals. The PK parameters listed in the box include the maximum drug concentration $\left(\mathrm{C}_{\max }\right)$, the area under the curve $(\mathrm{AUC})$ and the time taken to reach $\mathrm{C}_{\max }\left(\mathrm{T}_{\max }\right)$. 

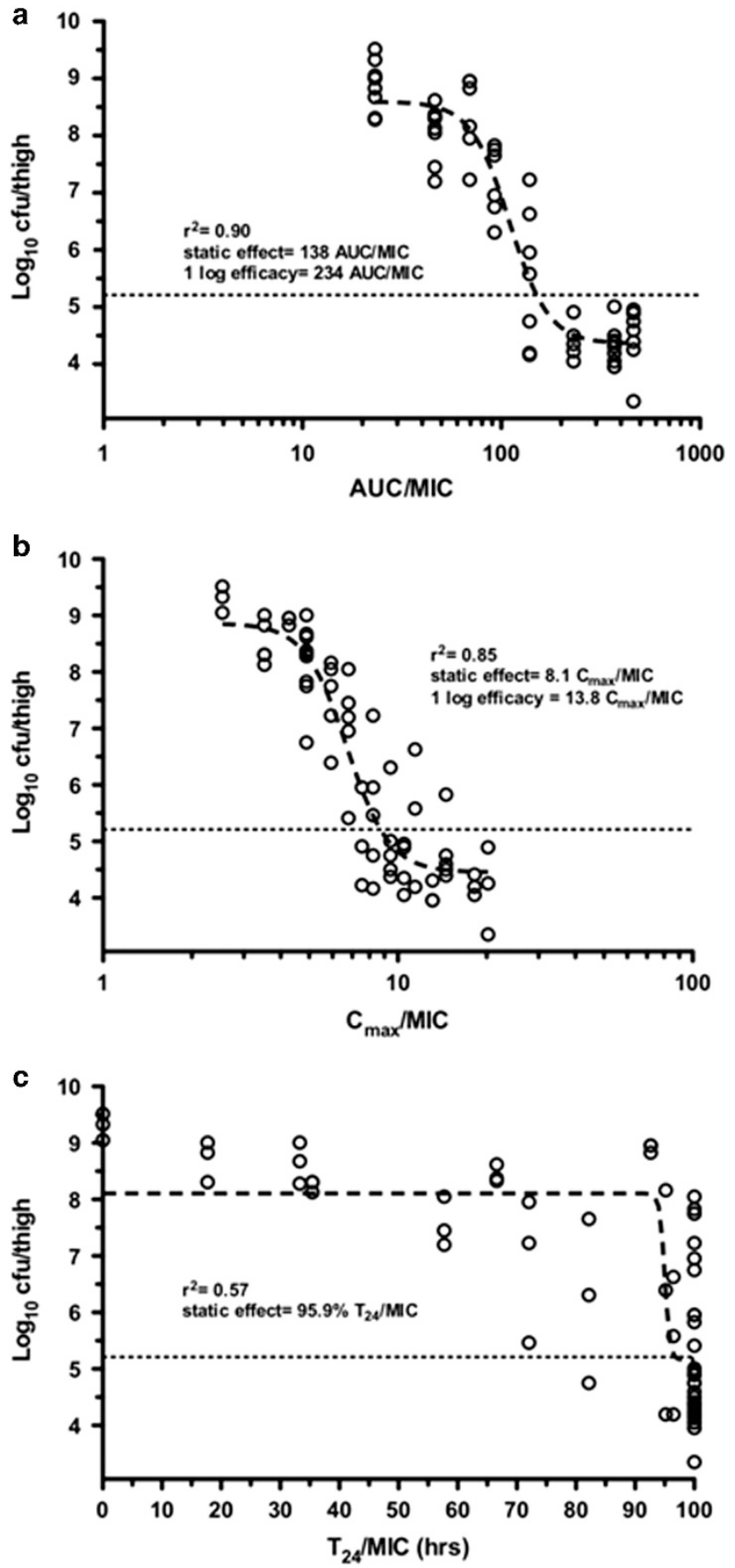

Figure 5 Relationship for methicillin-resistant Staphylococcus aureus (MRSA) UNT103-3 (NVB333 MIC is $4 \mathrm{mg} \mathrm{I}^{-1}$ ) between the $\log _{10}$ CFUs per thigh at $24 \mathrm{~h}$ and the pharmacokinetic/pharmacodynamic (PK/PD) indices area under the curve (AUC)/MIC (a), maximum drug concentration $\left(\mathrm{C}_{\max }\right) /$ MIC (b) and $\mathrm{T}_{24} / \mathrm{MIC}$ (c). Each symbol represents the datum from a single thigh. The dotted lines represent the mean bacterial burden in the thighs at the start of treatment.

AUC/MIC and 13.8 for $\mathrm{C}_{\max } / \mathrm{MIC}$. It is important to note that these calculations are based on total drug levels and not free unbound NVB333. It proved difficult to determine protein binding reliably using a rapid equilibrium device because of nonspecific binding; however, it is estimated that NVB333 was $\geqslant 90 \%$ protein bound.

\section{DISCUSSION}

The global surge of resistant pathogenic bacteria and growth in the identification of new mechanisms that confer resistance against current antibacterial agents emphasizes the need for new antibacterials particularly with novel mechanisms of action. Despite this the vast majority of many of the estimated 39 new antibiotics believed to be in clinical development ${ }^{19}$ represent modified versions of approved antibiotics. In attempts to widen the pool of potential novel antibacterials, attention has increasingly turned to alternative and perhaps previously overlooked classes of molecules, and among them the lantibiotics. ${ }^{6}$

NVB333 is the C-terminal 3,5-dichlorobenzylamine monocarboxamide derivative of the lantibiotic DAB. The compound emerged from a medicinal chemistry program aimed primarily at increasing the antibacterial activity of DAB against staphylococci and enterococci. NVB302, the diaminoheptane monocarboxamide C-terminal derivative of $\mathrm{DAB}$, emerged from a similar program aiming to enhance activity versus Clostridium difficile and is currently under development for the treatment of $C$. difficile infection. ${ }^{20}$ The antibacterial activity of NVB333 in vitro spans clinically relevant Gram-positive pathogens. Importantly, NVB333 retains its activity against strains with resistance to other important anti-MRSA antibiotics including vancomycin, daptomycin and linezolid as well as penicillin-resistant Streptococcus pneumoniae (data not shown). In addition, no spontaneous resistant isolates were detected when up to $10^{11} \mathrm{CFUs}$ of strains of $S$. aureus MRSA (strain R33, Health Protection Agency) and MSSA (strain SH1000 21), E. faecium ATCC 19579 (VSE) and S. pyogenes (clinical isolate, University of Leeds, Leeds general infirmary) were plated onto agar containing four times the respective MIC level of NVB333 (data not shown). This lack of resistance development is consistent with the assumed mode of action (lipid II binding) as established for actagardine. ${ }^{10}$

The modest in vitro activity of NVB333 belies its effectiveness in vivo as indeed has previously been noted for both mersacidin ${ }^{22}$ and actagardine. ${ }^{23}$ In a disseminated infection model, the $\mathrm{ED}_{50}$ value for survival over the course of 7 days was three times lower for NVB333 than required for vancomycin (despite the lower MIC of the latter). The strains of $S$. aureus challenged in the thigh infection models cover a range of susceptibilities to NVB333 and include two VISA clinical isolates with MICs equal to the $\mathrm{MIC}_{90}$ for NVB333. Although in vitro NVB333 is two to four times less active than vancomycin against each of these strains, in vivo the efficacy of NVB333 is comparable or greater than vancomycin, particularly in the case of the MRSA strains ATCC 33591 and UNT103-3. NVB333 was also active against a vancomycin-resistant $E$. faecalis in the thigh model at a similar dose as required for efficacy against $S$. aureus.

The PK/PD analysis of the thigh infection model ( $S$. aureus UNT103-3) was determined through dose fractionation studies of NVB333. Administration was through the s.c. route that enabled multiple dosing of animals over a 24 -h period. The PK parameters of NVB333 measured following s.c. administration show a delay and reduction in $\mathrm{C}_{\max }$ compared with i.v. dosing. The fractionation studies revealed that AUC/MIC was the index most predictive of the in vivo antibacterial effect of NVB333. AUC/MIC is the same PK/PD driver reported for daptomycin, vancomycin and NAI-107. Reported values of AUC/MIC (total drug) required to deliver a static effect for these three drugs were in a similar range that is, 169 to 608 (daptomycin ${ }^{24}$ ), 33 to 212 (vancomycin ${ }^{24}$ ) and 371 (NAI-107, mean level from multiple strains ${ }^{25}$ ), respectively. The AUC/MIC (total drug) of NVB333 required to achieve stasis was measured as 138. In the lung infection model NVB333 was more effective than vancomycin, 
reducing bacterial burdens to lower levels than vancomycin at comparable $\mathrm{mg} \mathrm{kg}^{-1}$ dose levels. Measurements of NVB333 in the ELF of infected lungs suggest the level of exposure is only $~ 2-3 \%$ of the plasma exposure (AUC) possibly because of the high protein binding of NVB333. However, because of the high plasma exposure this still represents useful therapeutic levels of NVB333 in the lung.

In all in vivo studies NVB333 was well tolerated at the dose levels used and there were no signs of any drug-related adverse effects. NVB333 has demonstrated comparable or greater activity than vancomycin at comparable dose levels $\left(\mathrm{mg} \mathrm{kg}^{-1}\right)$ in in vivo models against clinically relevant Gram-positive pathogens. In a period when the effectiveness of current antibacterial agents is increasingly challenged globally, NVB333 represents a novel class of antibacterial that warrants further investigation.

\section{CONFLICT OF INTEREST}

SB and MJD are shareholders of Novacta Biosystems, and MJD is on the board of directors for both Novacta Biosystems and Cantab Anti-infectives.

\section{ACKNOWLEDGEMENTS}

We thank MDS Pharma Services/Ricerca (now Eurofins Panlabs) for running the disseminated infection model and mouse thigh study using MRSA ATCC 33591. All other in vivo studies were carried out at the University of North Texas Health Science Center (UNTHSC). We also thank Eurofins Medinet for in vitro services. This work was partly supported by an R\&D Development grant (no. 5496) awarded to Novacta Biosystem from the UK government.

1 World Health Organisation. Antimicrobial resistance: global report on surveillance (2014)

2 Review on Antimicrobial Resistance. Antimicrobial resistance: tackling a crisis for the health and wealth of nations (2014).

3 U.S. Food and Drug Administration Center for Drug Evaluation and Research. Novel new drugs 2014 summary (2015).

4 Butler, M. S., Blaskovich, M. A. \& Cooper, M. A. Antibiotics in the clinical pipeline in 2013. J. Antibiot. 66, 571-591 (2013).

5 Fernebro, J. Fighting bacterial infections - future treatment options. Drug. Resist. Updat. 14, 125-139 (2011).

6 Dischinger, J., Chipalu, S. B. \& Bierbaum, G. Lantibiotics: promising candidates for future applications in health. Int. J. Med. Microbiol. 304, 51-62 (2014).

7 Boakes, S., Appleyard, A. N., Cortés, J. \& Dawson, M. J. Organization of the biosynthetic genes encoding deoxyactagardine $B(D A B)$, a new lantibiotic produced by Actinoplanes liguriae NCIMB41362. J. Antibiot. 63, 351-358 (2010).
8 Bierbaum, G. \& Sahl, H.-G. Lantibiotics: mode of action, biosynthesis and bioengineering. Curr. Pharm. Biotechnol. 10, 2-18 (2009).

9 Ling, L. L et al. A new antibiotic kills pathogens without detectable resistance. Nature 517, 455-459 (2015)

10 Brötz, H., Bierbaum, G., Leopold, K., Reynolds, P. E. \& Sahl, H.-G. The lantibiotic mersacidin inhibits peptidoglycan synthesis by targeting lipid II. Antimicrob. Agents. Chemother. 42, 154-160 (1998).

11 Jabés, D. et al. Efficacy of the new lantibiotic NAl-107 in experimental infections induced by multidrug-resistant Gram-positive pathogens. Antimicrob. Agents. Chemother. 55, 1671-1676 (2011).

12 Ghobrial, O., Derendorf, H. \& Hillman, J. D. Pharmacokinetic and pharmacodynamic evaluation of the lantibiotic MU1140. J. Pharm. Sci. 99, 2521-2528 (2010).

13 Febbraro, S., Hancock, A., Boyd, A. \& Dawson, M. J. Randomised, placebo-controlled, dose escalating study to assess the safety, tolerability, and pharmacokinetics of single and multiple doses of NVB302 administered orally to healthy volunteers. Abstracts of the fifty-second Interscience Conference on Antimicrobial Agents and Chemotherapy, abstr F1540C, San Francisco, CA (2012).

14 Clinical and Laboratory Standards Institute. Methods for dilution antimicrobial susceptibility test for bacteria that grow aerobically; approved standard CLSI Document M07-A9, 9th edn (Clinical Laboratory Standards Institute, Wayne, PA, USA, 2012).

15 Andes, D. \& Craig, W. A. In vivo activities of amoxicillin and amoxicillin-clavulanate against Streptococcus pneumoniae: application to breakpoint determinations. Antimicrob. Agents. Chemother. 42, 2375-2379 (1998).

16 Goldstein, B. P. et al. Antimicrobial activity of MDL 63,246 , a new semisynthetic glycopeptide antibiotic. Antimicrob. Agents. Chemother. 39, 1580-1588 (1995).

17 Weiss, W. J., Murphy, T., Lenoy, E. \& Young, M. In vivo efficacy and pharmacokinetics of AC98-6446, a novel cyclic glycopeptide, in experimental infection models. Antimicrob. Agents. Chemother. 48, 1708-1712 (2004).

18 Mishra, N. N. et al. In vitro cross-resistance to daptomycin and host defense cationic antimicrobial peptides in clinical methicillin-resistant Staphylococcus aureus isolates. Antimicrob. Agents. Chemother. 55, 4012-4018 (2011).

19 The PEW charitable trusts. December 17 2015. Antibiotics currently in clinical development. Antibiotic resistance project (September 2015). http://www.pewtrusts.org/ en/multimedia/data-visualizations/2014/antibiotics-currently-in-clinical-development. Accessed on 18 February 2016.

20 Boakes, S. \& Dawson, M.J. in Natural Products: Discourse, Diversity, and Design (eds Osbourn, A., Goss, R. J. \& Carter, G. T.) 455-468 (Wiley Blackwell, Oxford, UK, 2014).

21 Horsburgh, M. J. et al. SigmaB modulates virulence determinant expression and stress resistance: characterization of a functional rsbU strain derived from Staphylococcus aureus 8325-4. J. Bacteriol. 184, 5457-5467 (2002).

22 Chatterjee, S., Chatterjee, D. K., Jani, R. H., Blumbach, J. \& Ganguli, B. N. Mersacidin, a new antibiotic from Bacillus in vitro and in vivo antibacterial activity. $J$ Antibiot. 45, 839-845 (1992).

23 Malabarba, A., Pallanza, R., Berti, M. \& Cavalleri, B. Synthesis and biological activity of some amide derivatives of the lantibiotic actagardine. J. Antibiot. 43, 1089-1097 (1990).

24 Lee, D. G., Murakami, Y., Andes, D. R. \& Craig, W. A. Inoculum effect of ceftobiprole, daptomycin, linezolid, and vancomycin with Staphylococcus aureus and Streptococcus pneumoniae at inocula of $10^{5}$ and $10^{7} \mathrm{CFU}$ injected into opposite thighs of neutropenic mice. Antimicrob. Agents. Chemother. 57, 1434-1441 (2013).

25 Lepak, A. J. Marchillo, K. Craig, W. A. \& Andes, D. R. In vivo pharmacokinetics and pharmacodynamics of the lantibiotic NAI-107 in a neutropenic murine thigh infection model. Antimicrob. Agents. Chemother. 59, 1258-1264 (2015). 